\title{
An Affirmative Coping Skills Intervention to Improve the Mental and Sexual Health of Sexual and Gender Minority Youth (Project Youth AFFIRM): Protocol for an Implementation Study
}

Shelley L Craig ${ }^{1 *}, \mathrm{PhD}$; Lauren B McInroy ${ }^{2 *}, \mathrm{PhD}$; Andrew David Eaton ${ }^{1 *}, \mathrm{MSW}$; Gio Iacono ${ }^{1 *}, \mathrm{MSW}$; Vivian WY Leung $^{1 *}$, MA; Ashley Austin ${ }^{3 *}, \mathrm{PhD}$; Cheryl Dobinson ${ }^{4 *}$, MA

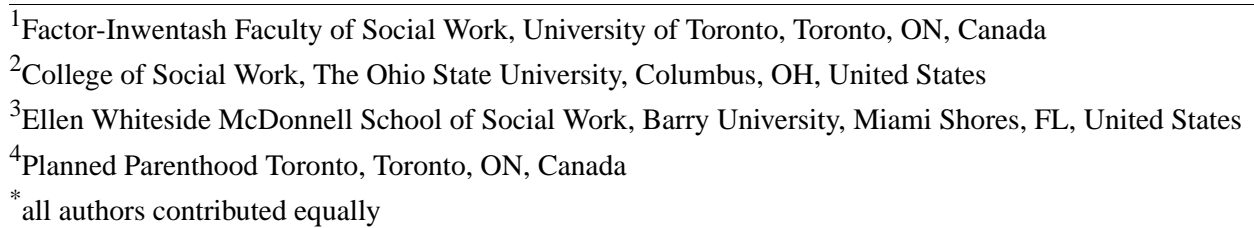

\section{Corresponding Author:}

Shelley L Craig, $\mathrm{PhD}$

Factor-Inwentash Faculty of Social Work

University of Toronto

246 Bloor St W

Toronto, ON, M5S 1V4

Canada

Phone: 14169788847

Email: shelley.craig@utoronto.ca

\section{Abstract}

Background: Sexual and gender minority youth (SGMY, aged 14-29 years) face increased risks to their well-being, including rejection by family, exclusion from society, depression, substance use, elevated suicidality, and harassment, when compared with their cisgender, heterosexual peers. These perils and a lack of targeted programs for SGMY exacerbate their risk for HIV and other sexually transmitted infections. Cognitive behavioral therapy (CBT) interventions support clients by generating alternative ways of interpreting their problems and beliefs about themselves. CBT, tailored to the experiences of SGMY, may help SGMY improve their mood and coping skills by teaching them how to identify, challenge, and change maladaptive thoughts, beliefs, and behaviors. Based on the promising results of a pilot study, a CBT-informed group intervention, AFFIRM, is being tested in a pragmatic trial to assess its implementation potential.

Objective: The aim of this study is to scale-up implementation and delivery of AFFIRM, an 8-session manualized group coping skills intervention focused on reducing sexual risk behaviors and psychosocial distress among SGMY. Our secondary aim is to decrease sexual risk taking, poor mental health, and internalized homophobia and to increase levels of sexual self-efficacy and proactive coping among SGMY.

Methods: SGMY are recruited via flyers at community agencies and organizations, as well as through Web-based advertising. Potential participants are assessed for suitability for the group intervention via Web-based screening and are allocated in a 2:1 fashion to the AFFIRM intervention or a wait-listed control in a stepped wedge wait-list crossover design. The intervention groups are hosted by collaborating community agency sites (CCASs; eg, community health centers and family health teams) across Ontario, Canada. Participants are assessed at prewait (if applicable), preintervention, postintervention, 6-month follow-up, and 12-month follow-up for sexual health self-efficacy and capacity, mental health indicators, internalized homophobia, stress appraisal, proactive and active coping, and hope. Web-based data collection occurs either independently or at CCASs using tablets. Participants in crisis are assessed using an established distress protocol.

Results: Data collection is ongoing; the target sample is 300 participants. It is anticipated that data analyses will use effect size estimates, paired sample $t$ tests, and repeated measures linear mixed modeling in SPSS to test for differences pre- and postintervention. Descriptive analyses will summarize data and profile all variables, including internal consistency estimates. Distributional assumptions and univariate and multivariate normality of variables will be assessed. 
Conclusions: AFFIRM is a potentially scalable intervention. Many existing community programs provide safe spaces for SGMY but do not provide skills-based training to deal with the increasingly complex lives of youth. This pragmatic trial could make a significant contribution to the field of intervention research by simultaneously moving AFFIRM into practice and evaluating its impact.

International Registered Report Identifier (IRRID)： DERR1-10.2196/13462

(JMIR Res Protoc 2019;8(6):e13462) doi: 10.2196/13462

\section{KEYWORDS}

sexual and gender minorities; youth; coping behavior; pragmatic clinical trial; cognitive behavioral therapy; implementation science

\section{Introduction}

\section{Intersecting Vulnerabilities of Sexual and Gender Minority Youth}

Compared with their cisgender, heterosexual peers [1-8], sexual and gender minority youth (SGMY, aged 14-29 years) face increased risks to their well-being, including rejection by family [9], exclusion from society [10], depression [10,11], substance use [12], elevated suicidality [13,14], and harassment [15-19]. In the pilot study that informed this protocol, participants attributed the stress of their SGM status as a significant contributor to their risks [20]. Yet, there remains a dearth of research and services for SGMY [21]. Existent risks and the lack of targeted programs [21-25] exacerbate their risk for HIV infection [12,26]. In 2013, nearly $25 \%$ of the 2090 Canadians diagnosed with HIV were aged between 15 and 29 years, and $43 \%$ of those youth contracted HIV through same-sex exposure (compared with only $26 \%$ in 2004) [12,26,27].

There is a particular lack of research with female-identified SGMY, who report higher rates of HIV-related risk behaviors than their male-SGMY and non-SGMY peers [28-37]. These risks include sex with multiple partners [28,29], unprotected vaginal intercourse [30], injection drug use [31], and pregnancy $[32,33]$. SGMY risk factors are further increased in female-identified SGMY, as they have higher rates of mental health concerns compared with male-identified SGMY, including depressive symptoms and suicidality at younger ages, suggesting earlier onset of co-occurring concerns [34-36].

Thus, multiple factors such as depression [10], sexual health-risk behaviors [31], discrimination [16] and perceptions that HIV is not a threat [28-30] may interact to exacerbate SGMYs' risk [3]. Female-identified SGMY - as well as transgender, gender diverse, and racialized SGMY-experience even greater vulnerabilities to mental health stressors, which in turn can exacerbate sexual health risk [38-40]. Holistic interventions that affirm SGMY identities and cultivate a sense of community, may mitigate these risks $[41,42]$. As nearly $70 \%$ of premature adult deaths are related to behaviors initiated in adolescence (eg, unsafe sex and substance abuse) [43], this age range is a critical period to implement interventions that help youth cope with the risks they experience.

\section{Theoretical Approach}

Syndemics, minority stress, and community-based research theories provide insight toward SGMY intervention development. Syndemics theory highlights social inequities as root causes of synergistic interaction of 2 or more coexistent issues (eg, SGMY status and depression) or mutually reinforcing epidemics (eg, HIV) contributing to health disparities among marginalized populations [40,44-47]. Vulnerable individuals may encounter lifelong adversity, particularly from social marginalization and stigma [45], posing a greater risk for problems $[44,46]$ that can lead to poorer sexual and health outcomes [47]. For SGMY, as the number of psychosocial health problems increases, the risk of major negative health outcomes also increases [47-49]. To comprehensively combat sexual health risks, overlapping vulnerabilities must be addressed concurrently $[48,49]$.

Minority stress theory posits that marginalized populations experience a unique form of stress because of conflict between their identities and social expectations [50-53]. It partially explains why SGMY encounter disproportionate chronic stress, discrimination, and victimization [52], which subsequently increases likelihood of sexual risk taking, depressive anxiety, and substance abuse disorders [52,53]. An influential stressor, internalized homophobia (negative beliefs about one's own SGMY status) [54], is related to unprotected sex [54,55] and increased depression [10]. Minority stress may increase internalized homophobia and stress-related cortisol production associated with heightened depression, anxiety, and suicidal ideation [50,54]. SGMY may not learn to cope with stressors through traditional means (eg, family or community support) [55-58], resulting in vulnerability to health and mental health threats [48] and increasing likelihood of engaging in risky behaviors [49]. As traditional approaches do not address many of the co-occurring stressors for SGMY, interventions that enhance coping skills are critical [59-82].

Building on a rich history of community engagement in HIV/AIDS service delivery, community-based research is critical to intervention development with SGMY, particularly in diverse communities [83-88]. Community-based approaches build on shared values, belief systems, and social practices, allowing for discussions of HIV and sexual health-risk behaviors in a culturally sensitive manner [84-87]. Youth interventions developed in partnership with community also have a much higher rate of agency adoption than those with only academic stakeholders [88]. It is increasingly recognized that future youth interventions must include nimble design and flexible delivery [89-91]. Community feasibility studies improve an intervention's implementation potential while maintaining rigor in evaluation [92,93]. 


\section{Affirmative Cognitive Behavioral Therapy}

Cognitive behavioral therapy (CBT) suggests that people's behaviors and emotions are influenced by their perceptions of life events [60-62] and how one interprets their situation will impact the way they feel or behave [63]. As an example, a person who is depressed may experience unhelpful interpretations or perceptions of themselves because of their problems and life events [61,62]. CBT interventions support clients by generating alternative ways of interpreting their problems and beliefs about themselves [59,63]. Generating alternative ways of thinking and beliefs may facilitate positive changes in one's behaviors and emotional states [64].

CBT tailored to the experiences of SGMY may help improve mood and increase coping by teaching youth how to identify, challenge and change maladaptive thoughts, beliefs, and behaviors [59,66,67]. Continuing to practice CBT skills after each session (ie, via an action plan) further strengthens adaptive and affirming beliefs and behaviors. This process may lead to changing deeply ingrained problematic ways of thinking and behaving [65-67]. The process of identifying and challenging unhelpful beliefs about sexual and genderidentities in an affirming and supportive environment may facilitate a decrease in internalized homo-, bi-, and transphobic cognitions and emotions and lead to improvement in mood and coping [67-69]. Ultimately, CBT within an affirmative therapeutic context can support SGMY in challenging maladaptive coping skills (eg, negative beliefs, isolation, substance misuse, and self-harm) and learning adaptive coping skills (eg, balanced thinking, enhancing social supports, and goal-setting) through education, modeling, practicing skills, and positive reinforcement [15,69].
CBT has been effective at treating depression and sexual health-risk behaviors among minority status adolescents [70-72] and lesbian, gay, bisexual, transgender, and queer (LGBTQ) adults $[66,72]$. However, its effectiveness for SGMY is largely unknown [69]. While the majority of studies do not assess long-term treatment gains, some evidence suggests that such interventions have mental and sexual health benefits for minority populations [79]. Longitudinal research is needed to determine the sustained effectiveness of CBT interventions on adolescent and young adult SGM populations [80]. A few existing studies show promise with sustained reductions in depression found at 12 months [76,77] and 18 months [78], as well as sexual risk of young men who have sex with men at 6 months [72]. Despite the calls for resilience and coping-based research and interventions for SGMY [80], scholarship has maintained a focus on negative health and psychosocial outcomes [81]. To date, no studies have identified the utility of a large-scale implementation of CBT tailored for community-based, diverse groups of SGMY and drawing on an affirmative approach. This study is designed to fill that gap.

\section{Methods}

\section{AFFIRM Structure}

This pragmatic trial is designed to evaluate AFFIRM, a manualized group intervention for SGMY, which follows the structure described in Textbox 1 and is described in more detail elsewhere [20]. 
Textbox 1. Description of AFFIRM intervention (session focus and session activities).

Session 1 focus

- Introduction to cognitive behavioral therapy (CBT), exploring lesbian, gay, bisexual, transgender, and queer (LGBTQ)+ identities, and understanding minority stress.

Session 1 activities

- Introductions

- $\quad$ Discussing the theory and purpose of CBT approaches

- $\quad$ Exploring stress and minority stress

- Understanding the causes of stress in our lives

Session 2 focus

- Understanding the impact of anti-LGBTQ attitudes and behaviors on stress.

Session 2 activities

- $\quad$ Check in and review

- Examining homophobia, heterosexism, and transphobia at the individual, institutional, and cultural level

- Identifying how these experiences impact thoughts, feelings, and behaviors

- $\quad$ Fostering strategies for both coping with and combating anti-LGBTQ discrimination at all levels

Session 3 focus

- Understanding how thoughts impact feelings.

Session 3 activities

- $\quad$ Check in and review

- Distinguishing between thoughts and feelings

- Exploring how thoughts influence feelings and behaviors

- Identifying counterproductive thinking patterns

- Recognizing negative self-talk and feelings of hopelessness

- $\quad$ Learning thought stopping

Session 4 focus

- Using thoughts to change feelings.

Session 4 activities

- Check in and review

- Increasing positive thinking and feelings of hope

- Changing negative thoughts to positive thoughts

- Challenging negative thinking and internalized homophobia/negative feelings through the ABCD (activating event, belief, consequence, and debate) method

Session 5 focus

- Exploring how activities impact feelings.

Session 5 activities

- $\quad$ Check in and review

- Examining the impact of various activities on feelings

- Identifying supportive and identity-affirming activities

- The impact of LGBTQ-affirming activities on feelings

Session 6 focus 
- Planning to overcome counterproductive thoughts and negative feelings.

Session 6 activities

- Check in and review

- Distinguishing between clear and unclear goals

- Identifying short, mid-, and long-term goals

- Creating a sexual health plan

- Fostering hope for the future

Session 7 focus

- Understanding the impact of minority stress and anti-LGBTQ attitudes or behaviors on social relationships.

Session 7 activities

- Check in and review

- Anti-LGBTQ discrimination can lead to feelings of discomfort around others

- Responding to discrimination or harassment in social situations

- Learning to be assertive

Session 8 focus

- Putting it all together: developing safe, supportive, and identity-affirming social networks.

Session 8 activities

- Check in and review

- Maintaining a healthy social network: attending to thoughts, expectations, feelings, and behaviors within relationships

- Identifying a plan for building a supportive network

\section{Research Questions, Hypotheses, and Objectives}

This project is intended to scale-up implementation and delivery of AFFIRM, an 8-session manualized group coping skills intervention focused on reducing sexual risk behaviors and psychosocial distress among SGMY. This project aims to decrease sexual risk taking, depression, and internalized homophobia and increase levels of sexual self-efficacy and proactive coping among SGMY (ages 14-29 years). This project has the following research questions:

1. To what extent can AFFIRM be feasibly implemented in a range of practice settings, such as community health centers, family health teams, and community-based organizations?

2. What are the facilitative conditions and implementation barriers to effective delivery of AFFIRM?

3. How does participation in an affirmative coping skills intervention (AFFIRM) impact the psychosocial distress and sexual self-efficacy of SGMY?

Given these research questions, the study has the following hypotheses:

Hypothesis 1: AFFIRM can be feasibly implemented in a range of practice settings, and SGMY will have high rates of acceptability of the intervention.

Hypothesis 2: SGMY participating in AFFIRM will show significantly greater decreases in psychosocial distress (eg, internalized stigma and depression) compared with wait-listed controls (ie, SGMY attending existing community programs).

Hypothesis 3: SGMY participating in AFFIRM will show significantly higher levels of sexual self-efficacy and coping compared with wait-listed controls.

\section{Eligibility Criteria}

\section{Inclusion and Exclusion Criteria}

Inclusion criteria are as follows:

- $\quad$ Aged 14 to 29 years at the time of screening

- Identifies as a sexual and/or gender minority

- $\quad$ Reads, writes, and speaks fluent English

- Is interested in participating in the 8-session AFFIRM Intervention.

Exclusion criteria are as follows:

- Assessed by the Facilitation Team to be in crisis (ie, high risk of suicidality)

- Warranting a more intensive intervention

\section{Trial Design}

This pragmatic quasi-experimental study uses a stepped wedge wait-list crossover design (SWWCD), whereby all participants receive the intervention in clusters [94-98]. SWWCD has been utilized in community-based research where traditional randomization with a no-treatment condition is unethical, unacceptable to community stakeholders, or not feasible [98]. 
This study will examine the effects of participating in an AFFIRM intervention group (each consisting of 6-10 participants) compared with wait-list for SGMY (ages 14-29 years).

\section{Randomization}

Randomization is not possible in this study because of participants' registration through various CCAS.

\section{Blinding}

Participants are not blinded as they know whether they are assigned to intervention or wait-listed control. Facilitators are blinded to outcome assessments as outcomes are administered via survey weblink.

\begin{abstract}
Allocation
Participants are allocated in an approximate 2:1 fashion to intervention: wait-listed control. This ratio is based on the availability of practice sites to implement AFFIRM in their clinical practices $[96,97]$. Importantly, similar to community programming, the groups are constructed to be developmentally appropriate. Participants in a particular intervention group are typically within an age range of 3 to 5 years. For example, a 14 year old would generally not be placed in a group with anyone older than 18 years. Groups of people aged between 18 and 29 years may have a broader age range, as developmental stage is not as relevant for established adults. AFFIRM also consists of mixed identity groups (eg, sexual identities and gender identities), based on community feedback. This means that a single intervention group could comprise SGMY from a range of identities. Many community organizations do not focus on 1 particular SGM subpopulation but instead serve all SGMY.
\end{abstract}

\section{Framework}

This pragmatic trial is designed to assess AFFIRM's implementation potential in real-world practice conditions.

\section{Study Setting}

Collaborating community agency sites (CCASs) in a variety of urban, suburban, and rural communities across Ontario, Canada, are hosting a series of AFFIRM intervention groups, each consisting of 6 to 10 SGMY (aged 14-29 years). At present, there are 23 CCAS, of which 12 are urban, 8 are suburban, and 3 are rural, with more communities likely to be added in subsequent years of the study.

\section{Justification}

Age group of 14 to 29 years have been identified as a crucial time for SGMY as they start to come out, address family issues, and transition to postsecondary education and early employment [1-3]; as such, this age may be the ideal time for an affirmative CBT intervention. As SGMY face greater well-being risks than their cisgender, heterosexual peers, queerness is also an important qualifier for this study [4-8]. This study focuses on English-speaking CCASs in Ontario. Commitment to an 8 -session intervention and exclusion because of crisis are criteria common to group intervention research [99].

\section{Interventions}

\section{AFFIRM Intervention (Experimental)}

AFFIRM aims to help SGMY develop coping skills through a combination of education (delivered by facilitators) and rehearsal (ie, simulation of real-life experiences) in a manner that affirms (ie, validates) participants' sexual and gender minority identities, as well as their experiences. Affirmations are explicated through (1) acknowledging and validating the unique struggles experienced by SGMY (eg, homophobia); (2) exploring how participants currently cope with SGM-specific stressors (eg, familial disapproval); (3) facilitating the development of realistic alternative ways of thinking and behaving that affirm youth identities and sexual health choices while integrating healthy ways of coping with internal/external stressors; and (4) enhancing social connection between participants. AFFIRM also includes an overview of sexually transmitted infections (STIs), HIV/AIDS and hepatitis C, and focuses on activities that promote harm reduction, such as a personalized sexual safety plan regardless of accumulated sexual experience. Each series of AFFIRM begins with an orientation session for introductions and discussion of the 8-session schedule. Each of the 8 group sessions of AFFIRM then consist of (1) warm-up/review; (2) discussion of session objectives; (3) behavioral activities; (4) practice and rehearsal; and (5) group reflection and summary.

\section{Wait-List (Control)}

If they choose, wait-listed participants will attend existing community programs, considered to be treatment as usual for community intervention studies. In a SWWCD study, sites offer iterations of the intervention in phases; individuals in this study will move from the wait-list to AFFIRM over time [94]. The wait-list time frame is minimized as much as possible to ensure an ethical research process. As it is increasingly acknowledged that evidence-based practice requires community and practice-based research [95], alternative intervention designs that are rigorous and work in the real world are needed. Such designs adapt to local needs and often have better intervention outcomes [96-100].

\section{Discontinuation Criteria}

Participants who are in crisis (eg, actively suicidal) at any point during their in-person participation in the AFFIRM intervention are immediately assessed, and appropriate steps are taken to address their individual situation-up to and including being taken to local support services or hospitals by AFFIRM facilitators. Participants who are in crisis are withdrawn from the intervention and the study. A distress protocol (Multimedia Appendix 1) and crisis response form (Multimedia Appendix 2) have been developed for AFFIRM facilitators and is systematically implemented throughout the intervention when participants indicate signs of distress. Importantly, to enhance participants' safety and well-being, as part of the Web-based data collection, participants are asked at various points if they need immediate help and are provided with immediate resources, including national crises organizations (such as Kids Help Phone Canada or the Trevor Project) with 24-hour counseling via 
phone, chat, and/or SMS text messaging (short message service, SMS).

\section{Protocol Adherence Strategy}

The Core Facilitation Team (delivering the AFFIRM intervention) comprises social workers with a master's degree who are trained in AFFIRM, who meet weekly with the principal investigator to review study progress and ensure protocol adherence. All iterations of AFFIRM implemented in this study are cofacilitated by (1) one of the members of the Core Facilitation Team and (2) 1 representative of the CCAS (eg, a social worker, nurse, or community worker) where the intervention group is being held or another community-based professional, all of whom are trained in the AFFIRM intervention.

\section{Concomitant Care and Interventions}

There are no restrictions on participant involvement in other studies and/or interventions as a result of their participation in this project. While this prevents accounting for confounding factors (eg, combined effect of participating in another intervention), the geographic context of services in Ontario is such that it is unlikely that participants would have access to SGMY-specific affirmative interventions outside of this study.

\section{Outcomes}

\section{Primary}

The primary outcomes of this study are feasibility and acceptability. Feasibility will be measured by (1) number of sites that implement AFFIRM; (2) number of times each site runs the AFFIRM intervention; (3) availability of facilitators; and (4) number of participants that enroll, commence, and complete the intervention. Acceptability will be assessed through mixed-method participant and facilitator evaluations.

\section{Secondary}

This study's secondary outcome is implementation fidelity, that is, how closely AFFIRM facilitators adhere to the manualized intervention. This will be assessed through analysis of session audio recordings and facilitator process notes by analysts separate from the Core Facilitation Team.

\section{Exploratory}

Exploratory outcomes include changes in sexual health self-efficacy and capacity, mental health indicators, internalized homophobia, stress appraisal, proactive and active coping, and hope. These outcomes will be assessed through measures such as: the Sexual Health Capacity Scale [100], the Abstinence and Protection Self-Efficacy Scale [101], the Beck Depression
Inventory-II [102], the Diagnostic and Statistical Manual of Mental Disorders-V (DSM-V) Self-Rated Level 1 Cross-Cutting Symptom Measure-Child [103], the Stress Appraisal Measure for Adolescents [104], the Brief COPE [105], the Proactive Coping Inventory for Adolescents-A [106], the Adult Hope Scale [107], the Internalized Homophobia Scale [108], the Current Mood Scale [109], the Everyday Discrimination Scale [110], and the LGBTQ Microaggession Scale [111] (see Table 1).

\section{Data Collection}

AFFIRM participant data are exclusively collected using Web-based surveys, each of which takes approximately $20 \mathrm{~min}$ to complete. However, data collection takes place in 2 different settings: (1) via tablets (eg, Android tablets) while at the intervention locations (ie, some Web-based screenings, some pre- and posttests); and (2) independently Web-based (eg, some Web-based screenings, some pretests, or follow-ups). Secure collection of data is facilitated by the use of software with secure servers (Qualtrics). Instead of a unique identifier, which participants could forget over the course of the year, participants report their name, age, date of birth, 2 email addresses, gender identity, and sexual orientation at each time point.

\section{Measures}

All measures are completed at all time points, including demographics, as identities and circumstances are generally very flexible for SGMY because of their developmental stage, marginalized sexual and/or gender identities, and contextual circumstances. Measures include the following: (1) demographics (eg, age, sexual identity, gender identity, ethno-racial identity, and socioeconomic-status); (2) sexual health self-efficacy and capacity, including sexual health capacity [100] and abstinence and protection self-efficacies [101]; (3) mental health, including current mood [109], depression [102], and DSM-V cross-cutting symptoms [103]; (4) coping, including proactive coping [105] and coping strategies such as active coping, denial, and humor [106]; (5) stress appraisal, including perceiving stress as challenge or threat, and seeking out resources to overcome stress [104]; (6) hope, including agency and planning to meet goals [107]; (7) experiences with everyday discrimination [110]; (8) internalized homophobia [108]; (9) microaggressions, including interpersonal and environmental microaggressions [111]; (10) AFFIRM Satisfaction Survey, a 20-item questionnaire developed for AFFIRM completed after intervention delivery, which includes questions regarding (1) satisfaction, (2) overall experience, and (3) suggestions for improvement. For details of adaptation of existing survey measures, please see Table 1. 
Table 1. Survey instruments.

\begin{tabular}{|c|c|c|c|}
\hline Construct & Scale, study & Items & Modification \\
\hline \multirow[t]{3}{*}{$\begin{array}{l}\text { Sexual health self-efficacy } \\
\text { and capacity }\end{array}$} & Sexual Health Capacity Scale [100] & 5 & $\begin{array}{l}\text { Change scale from 5-point (1-5) to 4-point (1-4); Excluded } \\
2 \text { items; Added } 1 \text { item: "I understand how my mental and } \\
\text { sexual health are connected." }\end{array}$ \\
\hline & Abstinence Self-efficacy Scale [101] & 4 & Excluded 6 items; Wordings modified \\
\hline & Protection Self-efficacy Scale [89] & 8 & $\begin{array}{l}\text { Added } 4 \text { items: "I can ask for/get a test for HIV and STIs } \\
\text { from a doctor, Planned Parenthood, or a clinic."; "I can } \\
\text { read or think about my sexual health plan before having } \\
\text { sex."; "I can access/get information about my sexual health } \\
\text { (websites, agencies, trusted adults, professionals, or } \\
\text { friends)."; "I can manage my own sexual health."; Word- } \\
\text { ings modified }\end{array}$ \\
\hline \multirow[t]{3}{*}{ Mental health } & Beck Depression Inventory-II [102] & 20 & No modifications \\
\hline & $\begin{array}{l}\text { DSM- } 5^{\text {a }} \text { Self-Rated Level } 1 \text { Cross-Cutting } \\
\text { Symptom Measure-Child [103] }\end{array}$ & 20 & $\begin{array}{l}\text { Excluded } 5 \text { items from section } 9 \text { (Psychosis) and } 10 \\
\text { (Repetitive Thoughts and Behaviors); Slightly modified } 1 \\
\text { item }\end{array}$ \\
\hline & Current Mode Scale [109] & 6 & Wordings simplified \\
\hline \multirow[t]{2}{*}{ Coping } & Brief COPE [105] & 28 & 2 items slightly modified \\
\hline & $\begin{array}{l}\text { Proactive Coping Inventory for Adolescents- } \\
\text { A-Reflective Coping subscale [106] }\end{array}$ & 11 & 4 items slightly modified \\
\hline Stress appraisal & Stress Appraisal Measure for Adolescents [104] & 13 & 1 item excluded; 1 item slightly modified \\
\hline Hope & Adult Hope Scale [107] & 12 & No modifications \\
\hline Internalized homophobia & Internalized homophobia [108] & 10 & $\begin{array}{l}\text { Separated into } 2 \text { sections for microaggressions toward } \\
\text { sexual orientation and gender identity minorities }\end{array}$ \\
\hline \multirow{3}{*}{$\begin{array}{l}\text { Discrimination and } \\
\text { microaggressions }\end{array}$} & Everyday Discrimination Scale [110] & 7 & 2 items excluded; 1 item slightly modified \\
\hline & $\begin{array}{l}\text { LGBTQ }^{b} \text { Microaggressions Scale—Interpersonal } \\
\text { subscale [111] }\end{array}$ & 10 & $\begin{array}{l}\text { Excluded } 10 \text { items; Separated into } 2 \text { sections for microag- } \\
\text { gressions toward sexual orientation and gender identity } \\
\text { minorities }\end{array}$ \\
\hline & $\begin{array}{l}\text { LGBTQ Microaggressions Scale-Environmen- } \\
\text { tal subscale [111] }\end{array}$ & 5 & $\begin{array}{l}\text { Excluded } 2 \text { items; Added } 2 \text { items: "In my online environ- } \\
\text { ment it was OK to make jokes about LGBTQ+ people." } \\
\text { and "I heard or read someone making fun of chosen pro- } \\
\text { nouns." }\end{array}$ \\
\hline
\end{tabular}

${ }^{\text {a }}$ DSM-5: Diagnostic and Statistical Manual of Mental Disorders, $5^{\text {th }}$ edition.

${ }^{\mathrm{b}}$ LGBTQ: lesbian, gay, bisexual, transgender, and queer.

\section{Participant Timeline}

Table 2 shows the schedule of events. Participants complete a Web-based screening questionnaire, which includes their preferred site to participate in AFFIRM. For every 2 participants allocated to the intervention-only group, 1 participant is allocated to the wait-list group. The intervention-only group completes 4 data collection time points (pretest, posttest, 6-month follow-up, and 12-month follow-up). The wait-list group completes 5 data collection time points (prewait, pretest, posttest, 6-month follow-up, and 12-month follow-up). The prewait survey is completed immediately following their wait-listed control allocation, so that the pretest for the wait-list group serves as the follow-up on outcomes for the control group. Participants complete the pretests and posttests before the first week and at the last week of the intervention, respectively. The
Web-based pretest is completed independently shortly before the first group session. The posttest is completed on tablets (eg, Android tablets) at the intervention location following the final group session. Participants complete the prewait (if applicable), the 6-month follow-up, and the 12-month Web-based independent follow-up. Participants are reminded to participate via email and provided the link to the survey. If participants do not participate following the initial email, up to 2 follow-up emails are sent as reminders for each time point. The follow-up emails are sent at 2 weeks and 4 weeks after the initial email (ie, every 2 weeks for 1 month). If participants indicated in their Web-based screening that SMS text message or phone call is their preferred form of communication, they also receive follow-up SMS text messages at 2 to 4 weeks after the initial email. 
Table 2. Schedule of events.

\begin{tabular}{|c|c|c|c|c|c|c|c|c|}
\hline \multirow{2}{*}{$\begin{array}{l}\text { Visit details } \\
\text { Visit name }\end{array}$} & \multicolumn{3}{|c|}{ Screening period } & \multicolumn{3}{|c|}{$\begin{array}{l}\text { Study period (facilitator meeting; } \\
8 \text { weekly, 1-hour sessions) }\end{array}$} & \multicolumn{2}{|c|}{ Follow-up period } \\
\hline & $\begin{array}{l}\text { Screening } \\
\text { survey }\end{array}$ & Prewait & Pretest & Orientation & Sessions 1-8 & Posttest & $\begin{array}{l}\text { 6-month } \\
\text { follow-up }\end{array}$ & $\begin{array}{l}\text { 12-month } \\
\text { follow-up }\end{array}$ \\
\hline Visit number. & -3 & -2 & -1 & 0 & $1,2,3,4,6,7,8$ & 8 & 9 & 10 \\
\hline Week number & -8 to 0 & -8 to 0 & -8 to 0 & 0 & $1-8$ & 8 & 32 & 56 \\
\hline Day number & -56 to 0 & -56 to 0 & -56 to 0 & $1-56$ & $1-56$ & $1-56$ & $\begin{array}{l}+224 \text { to } \\
+238\end{array}$ & $\begin{array}{l}+392 \text { to } \\
+406\end{array}$ \\
\hline Visit window & \pm 56 & \pm 14 & \pm 0 & \pm 0 & \pm 0 & \pm 0 & \pm 14 & \pm 14 \\
\hline \multicolumn{9}{|l|}{ Procedures } \\
\hline Written informed consent & $X^{a}$ & ${ }^{b}$ & - & - & - & - & - & - \\
\hline Entry criteria assessment & $X$ & - & - & - & - & - & - & - \\
\hline Participant demographics & $X$ & - & - & - & - & - & - & - \\
\hline $\begin{array}{l}\text { Group session (intervention or } \\
\text { wait-listed control) }\end{array}$ & $\mathrm{X}$ & - & - & - & - & - & - & - \\
\hline Facilitator process notes & - & - & - & $\mathrm{X}$ & $X$ & - & - & - \\
\hline $\begin{array}{l}\text { Sexual health self-efficacy and } \\
\text { capacity }\end{array}$ & - & $\mathrm{X}$ & $X$ & - & - & $X$ & $\mathrm{X}$ & $X$ \\
\hline Mental health & - & $X$ & $X$ & - & - & $X$ & $X$ & $X$ \\
\hline Internalized queerness & - & $X$ & $X$ & - & - & $X$ & $X$ & $X$ \\
\hline Coping & - & $\mathrm{X}$ & $\mathrm{X}$ & - & - & $\mathrm{X}$ & $\mathrm{X}$ & $\mathrm{X}$ \\
\hline Hope & - & X & X & - & - & X & X & X \\
\hline
\end{tabular}

${ }^{\mathrm{a}}$ Procedure conducted.

${ }^{\mathrm{b}}$ Not applicable.

\section{Sample Size}

Approximately 300 participants will participate in AFFIRM. Each CCAS has agreed to complete a minimum of 1 AFFIRM iteration, comprising 1 intervention group and 1 wait-list group. This sample was primarily determined to assess the implementation-based outcomes. In addition, this sample would be sufficient for analysis of exploratory objectives, as described below.

\section{Recruitment}

Potential participants are recruited in multiple ways (1) via CCASs and other local community organizations (which are provided with flyers and cards directing potential participants to the independent Web-based screening); (2) via emails to local organizations and community groups serving SGMY (which are provided e-versions of the flyers and cards); and (3) Web-based postings on Facebook and Instagram. The Web-based postings involve geographically and demographically targeted paid boosts using Facebook's Ad Manager.

\section{Data Management and Monitoring}

Data are downloaded from Qualtrics, cleaned, and saved as password-protected files on an encrypted research drive. After data collection and cleaning for the entire study is completed, the data will then be deleted from Qualtrics servers. A data monitoring committee is not required at this stage, as the current phase is primarily focused on implementation acceptability in community sites; however, one will be formed before instigation of a larger trial.

\section{Harms}

As a psychosocial study, risks for adverse effects are negligible or nonexistent. The study's distress plan, discussed above, will be used if participants present in crisis.

\section{Ethics and Dissemination}

This study has been approved by the University of Toronto's HIV/AIDS Research Ethics Board (protocol ID\#35229). As an uncontrolled, nonrandomized trial, registration at this stage was not completed. If this implementation stage proves promising and the study proceeds to a full-scale multicenter trial, a new protocol will be registered and submitted for publication before participant enrollment.

\section{Results}

It is anticipated that data analyses will use effect size estimates, paired sample $t$ tests, and repeated measures linear mixed modeling (LMM) using SPSS to test for differences pre- and postintervention [112-114]. Descriptive analyses will summarize data and profile all variables, including internal consistency estimates. Distributional assumptions, univariate, and 
multivariate normality of all variables will be assessed. Data determined to be missing at random will be imputed with the expectation-maximization method with importance re-sampling [113].

Clinically significant change estimates and repeated measures LMM will be used to compare the influence of participation in AFFIRM to wait-list on sexual health self-efficacy and capacity, internalized queerness, hope, and depression of SGMY [114]. To test the influence of intervention on multiple outcomes, LMM using both time and interaction terms will be fit using SPSS [115,116]. Repeated measures LMM is considered an improvement over classical repeated measures analyses (eg, repeated measures analysis of variance) because of frequent correlated errors and nonindependence of observations that are forbidden by the assumptions of standard general linear approaches [114-116]. LMM also allows for the exploration of time effects, which is a potential source of confounding because of the partially randomized nature of the design and assumption of no interaction between intervention effects and time [117]. A total of 2 mixed models will be constructed to test the relationship between the intervention condition (AFFIRM group or the treatment as usual or wait-list [TAU/WL] group) and change in outcome variables from pre- to postintervention. Model 1 will include time and condition and will indicate whether there is a significant change in outcome variables over time and if significant cross-sectional associations between treatment condition and outcome variables exist. In model 2, interaction terms will be added to assess the longitudinal associations between treatment condition and the change (slope) of outcome variable scores from pre- to postintervention. The interaction of multiple intersecting identities as well as site, group, and individual-level covariates will be included in this analysis. The impact of behavioral interventions also can be identified through effect size [114]. The potential clinical significance of AFFIRM will be assessed by calculating Cohen $d$ effect sizes, comparing percentages of participants at 2 time points. It is expected that compared with the TAU/WL group, the AFFIRM group will show statistically significant change in hypothesized outcomes. The use of similar sample sizes with multiple time points and measures is considered appropriate [112] and allows for analysis of change effects using data points. The qualitative data collected through the acceptability measures will be analyzed using content analysis with ATLAS.ti software by a minimum of 3 coders [118].

\section{Discussion}

AFFIRM is a potentially scalable intervention for SGMY as (1) AFFIRM fosters positive health behaviors by identifying and modifying less healthy behaviors; (2) participants learn how to better cope with minority stressors by rehearsing and having facilitators validate these emerging coping skills; and (3) AFFIRM's pilot showed positive results on mental and sexual health outcomes [20]. Other CBT-informed group interventions have been effective in reducing adolescent depression and sexual risk, improving mood and behavior, increasing HIV and STI knowledge, and improving self-efficacy [58-60]. This study's exploratory measures will assess if AFFIRM results in similar outcomes. Group interventions offer SGMY opportunities to learn, observe, and practice skills [79,89], as well as obtain support from peers experiencing similar difficulties [76,77]. Many existing community programs provide safe spaces for SGMY but do not provide skills-based training to deal with the increasingly complex lives of adolescents and young adults This pragmatic trial could make a significant contribution to the field of intervention research by simultaneously moving AFFIRM into practice and evaluating its impact.

\section{Acknowledgments}

SLC is the Canada Research Chair in Sexual and Gender Minority Youth. This project is funded by a Partnership Grant from the Social Sciences and Humanities Research Council of Canada (SSHRC \#895-2018-1000) with funding for evaluation activities from the Public Health Agency of Canada (PHAC \#1718-HQ-000697). ADE is supported by a salary award from the Ontario HIV Treatment Network. The authors would like to thank Bonnie Lao for her assistance with this article.

\section{Conflicts of Interest}

None declared.

\section{Multimedia Appendix 1}

Distress protocol for AFFIRM intervention.

[DOCX File, 15KB-Multimedia Appendix 1]

\section{Multimedia Appendix 2}

AFFIRM crisis response form.

[DOCX File, 18KB-Multimedia Appendix 2]

\section{References}

1. Scourfield J, Roen K, McDermott L. Lesbian, gay, bisexual and transgender young people's experiences of distress: resilience, ambivalence and self-destructive behaviour. Health Soc Care Community 2008 May;16(3):329-336. [doi: 10.1111/j.1365-2524.2008.00769.x] [Medline: 18328055$]$ 
2. Benibgui M. Mental Health Challenges and Resilience in Lesbian, Gay, And Bisexual Young Adults : Biological and Psychological Internalization of Minority Stress and Victimization. Montreal, QC, Canada: Concordia University Library; 2010.

3. Horn SS, Kosciw JG, Russell ST. Special issue introduction: new research on lesbian, gay, bisexual, and transgender youth: studying lives in context. J Youth Adolesc 2009 Aug;38(7):863-866. [doi: 10.1007/s10964-009-9420-1] [Medline: 19636731]

4. Williams T, Connolly J, Pepler D, Craig W. Peer victimization, social support, and psychosocial adjustment of sexual minority adolescents. J Youth Adolescence 2005 Oct;34(5):471-482. [doi: 10.1007/s10964-005-7264-x]

5. Hoffman ND, Freeman K, Swann S. Healthcare preferences of lesbian, gay, bisexual, transgender and questioning youth. J Adolesc Health 2009 Sep;45(3):222-229 [FREE Full text] [doi: 10.1016/j.jadohealth.2009.01.009] [Medline: 19699417]

6. Craig SL. Precarious partnerships: designing a community needs assessment to develop a system of care for gay, lesbian, bisexual, transgender and questioning (GLBTQ) youth. J Community Pract 2011 Jul;19(3):274-291. [doi:

10.1080/10705422.2011.595301]

7. Cross T, Friesen B, Jivanjee P, Gowen K, Bandurraga A, Matthew C, et al. Defining youth success using culturally appropriate community-based participatory research methods. Best Pract Ment Health 2011;7(1):94-114 [FREE Full text]

8. D'augelli AR, Grossman AH, Starks MT. Families of gay, lesbian, and bisexual youth: what do parents and siblings know and how do they react? J GLBT Fam Stud 2008 Apr 17;4(1):95-115. [doi: 10.1080/15504280802084506]

9. Ueno K. Sexual orientation and psychological distress in adolescence: examining interpersonal stressors and social support processes. Soc Psychol Q 2005 Sep;68(3):258-277. [doi: 10.1177/019027250506800305]

10. Martin-Storey A, Crosnoe R. Sexual minority status, peer harassment, and adolescent depression. J Adolesc 2012 Aug;35(4):1001-1011 [FREE Full text] [doi: 10.1016/j.adolescence.2012.02.006] [Medline: 22401842]

11. Mustanski B, Andrews R, Herrick A, Stall R, Schnarrs PW. A syndemic of psychosocial health disparities and associations with risk for attempting suicide among young sexual minority men. Am J Public Health 2014 Feb;104(2):287-294. [doi: 10.2105/AJPH.2013.301744] [Medline: 24328641]

12. Public HAOC. Canada.ca. 2014. HIV/AIDS in Canada: Surveillance report to December 31st, 2013 URL: https://www. canada.ca/content/dam/phac-aspc/migration/phac-aspc/aids-sida/publication/survreport/2013/dec/assets/pdf/ hiv-aids-surveillence-eng.pdf [accessed 2019-05-17] [WebCite Cache ID 78ROVJ0Sg]

13. Dysart-Gale D. Social justice and social determinants of health: lesbian, gay, bisexual, transgendered, intersexed, and queer youth in Canada. J Child Adolesc Psychiatr Nurs 2010;23(1):23-28. [doi: 10.1111/j.1744-6171.2009.00213.x] [Medline: 20122085]

14. Davis TS, Saltzburg S, Locke CR. Supporting the emotional and psychological well being of sexual minority youth: youth ideas for action. Child Youth Serv Rev 2009 Sep;31(9):1030-1041. [doi: 10.1016/j.childyouth.2009.05.003] [Medline: 25904163]

15. Saewyc EM, Skay CL, Hynds P, Pettingell S, Bearinger LH, Resnick MD, et al. Suicidal ideation and attempts in North American school-based surveys: are bisexual youth at increasing risk? J LGBT Health Res 2008 Oct 11;3(2):25-36. [doi: $10.1300 / \mathrm{J} 463 \mathrm{v} 03 \mathrm{n} 02$ 04]

16. Meyer IH, Dietrich J, Schwartz S. Lifetime prevalence of mental disorders and suicide attempts in diverse lesbian, gay, and bisexual populations. Am J Public Health 2008 Jun;98(6):1004-1006. [doi: 10.2105/AJPH.2006.096826] [Medline: 17901444]

17. Ryan C, Huebner D, Diaz RM, Sanchez J. Family rejection as a predictor of negative health outcomes in white and Latino lesbian, gay, and bisexual young adults. Pediatrics 2009 Jan;123(1):346-352. [doi: 10.1542/peds.2007-3524] [Medline: 19117902]

18. Doty ND, Willoughby BL, Lindahl KM, Malik NM. Sexuality related social support among lesbian, gay, and bisexual youth. J Youth Adolesc 2010 Oct;39(10):1134-1147. [doi: 10.1007/s10964-010-9566-x] [Medline: 20593304]

19. Birkett M, Espelage DL, Koenig B. LGB and questioning students in schools: the moderating effects of homophobic bullying and school climate on negative outcomes. J Youth Adolesc 2009 Aug;38(7):989-1000. [doi: 10.1007/s10964-008-9389-1] [Medline: 19636741]

20. Craig SL, Austin A. The AFFIRM open pilot feasibility study: A brief affirmative cognitive behavioral coping skills group intervention for sexual and gender minority youth. Child Youth Serv Rev 2016 May;64:136-144. [doi: 10.1016/j.childyouth.2016.02.022]

21. Berlan ED, Corliss HL, Field AE, Goodman E, Austin SB. Sexual orientation and bullying among adolescents in the growing up today study. J Adolesc Health 2010 Apr;46(4):366-371 [FREE Full text] [doi: 10.1016/j.jadohealth.2009.10.015] [Medline: 20307826]

22. DiPlacido J. Minority stress among lesbians, gay men,bisexuals: a consequence of heterosexism, homophobia,stigmatization. In: Stigma and Sexual Orientation: Understanding Prejudice Against Lesbians, Gay Men and Bisexuals. Thousand Oaks, CA: Sage Publications; 1998:138-159.

23. Detrie PM, Lease SH. The relation of social support, connectedness, and collective self-esteem to the psychological well-being of lesbian, gay, and bisexual youth. J Homosex 2007;53(4):173-199. [doi: 10.1080/00918360802103449] [Medline: 18689197$]$ 
24. Statistics Canada. Ottawa: Statistics Canada; 2018. A portrait of Canadian youth URL: https://www150.statcan.gc.ca/n1/ pub/11-631-x/11-631-x2018001-eng.htm [accessed 2019-05-17] [WebCite Cache ID 78ROsPGGY]

25. Canada.ca. 2014. Population-specific status report: HIV/AIDS and other sexually transmitted and blood borne infections among youth in Canada URL: https://www.canada.ca/en/public-health/services/hiv-aids/publications/ population-specific-hiv-aids-status-reports/hiv-aids-other-sexually-transmitted-blood-borne-infections-among-youth-canada. html [accessed 2019-05-17] [WebCite Cache ID 78RP3MMbd]

26. Goodenow C, Szalacha LA, Robin LE, Westheimer K. Dimensions of sexual orientation and HIV-related risk among adolescent females: evidence from a statewide survey. Am J Public Health 2008 Jun;98(6):1051-1058. [doi: 10.2105/AJPH.2005.080531]

27. Travers R, Paoletti D. Responding to the support needs of HIV positive lesbian, gay and bisexual youth. Can J Hum Sex 1999;8(4):271-284 [FREE Full text]

28. Saewyc E, Skay C, Richens K, Reis E, Poon C, Murphy A. Sexual orientation, sexual abuse, and HIV-risk behaviors among adolescents in the pacific northwest. Am J Public Health 2006 Jun;96(6):1104-1110. [doi: 10.2105/AJPH.2005.065870] [Medline: 16670224$]$

29. Thoma BC, Huebner DM, Rullo JE. Unseen risks: HIV-related risk behaviors among ethnically diverse sexual minority adolescent females. AIDS Educ Prev 2013 Dec;25(6):535-541. [doi: 10.1521/aeap.2013.25.6.535] [Medline: 24245599]

30. Saewyc E. Adolescent pregnancy among lesbian, gay, and bisexual teens. In: Cherry AL, Dillon ME, editors. International Handbook of Adolescent Pregnancy. New York, NY: Springer; 2014:159-169.

31. Saewyc E. Research on adolescent sexual orientation: development, health disparities, stigma, and resilience. J Res Adolesc 2011;21(1):256-272. [doi: 10.1111/j.1532-7795.2010.00727.x] [Medline: 27099454]

32. Gangamma R, Slesnick N, Toviessi P, Serovich J. Comparison of HIV risks among gay, lesbian, bisexual and heterosexual homeless youth. J Youth Adolesc 2008;37(4):456-464 [FREE Full text] [doi: 10.1007/s10964-007-9171-9] [Medline: $\underline{18607514]}$

33. Canadian Mental Health Association. 2013. Fast facts about mental illness URL: https://cmha.ca/about-cmha/ fast-facts-about-mental-illness [accessed 2019-05-17] [WebCite Cache ID 78RRhEShe]

34. Diane B. Sexual Orientation And Victimization. Ottawa, ON, Canada: Statistics Canada, Canadian Centre For Justice Statistics; 2004.

35. Hatzenbuehler ML, McLaughlin KA, Xuan Z. Social networks and risk for depressive symptoms in a national sample of sexual minority youth. Soc Sci Med 2012 Oct;75(7):1184-1191. [doi: 10.1016/j.socscimed.2012.05.030] [Medline: 22771037]

36. Taylor C, Peter T. Egale Canada. 2011. Every class in every school: the first national climate survey on homophobia, biphobia, and transphobia in Canadian schools 2011 URL: https://egale.ca/wp-content/uploads/2011/05/EgaleFinalReport-web. pdf [accessed 2019-05-17] [WebCite Cache ID 78RRvw4yO]

37. Craig SL, McInroy L. The relationship of cumulative stressors, chronic illness and abuse to the self-reported suicide risk of black and hispanic sexual minority youth. J. Community Psychol 2013 Jul 22;41(7):783-798. [doi: 10.1002/jcop.21570]

38. Stall R, Mills TC, Williamson J, Hart T, Greenwood G, Paul J, et al. Association of co-occurring psychosocial health problems and increased vulnerability to HIV/AIDS among urban men who have sex with men. Am J Public Health 2003 Jun;93(6):939-942. [doi: 10.2105/AJPH.93.6.939] [Medline: 12773359]

39. Craig SL, McInroy L. You can form a part of yourself online: the influence of new media on identity development and coming out for LGBTQ youth. J Gay Lesbian Ment Health 2014 Jan 30;18(1):95-109. [doi: 10.1080/19359705.2013.777007]

40. Resnick MD, Catalano RF, Sawyer SM, Viner R, Patton GC. Seizing the opportunities of adolescent health. Lancet 2012 Apr 28;379(9826):1564-1567. [doi: 10.1016/S0140-6736(12)60472-3] [Medline: 22538176]

41. Marshal MP, Dermody SS, Cheong J, Burton CM, Friedman MS, Aranda F, et al. Trajectories of depressive symptoms and suicidality among heterosexual and sexual minority youth. J Youth Adolesc 2013 Jun 20;42(8):1243-1256. [doi: 10.1007/s10964-013-9970-0] [Medline: 23784511]

42. Ferlatte O, Hottes TS, Trussler T, Marchand R. Evidence of a syndemic among young Canadian gay and bisexual men: uncovering the associations between anti-gay experiences, psychosocial issues, and HIV risk. AIDS Behav 2014 Jul;18(7):1256-1263. [doi: 10.1007/s10461-013-0639-1] [Medline: 24129844]

43. Singer M. Introduction to Syndemics: A Critical Systems Approach to Public and Community Health. Hoboken, NJ: Wiley, John \& Sons, Incorporated; 2009.

44. Stall R, Friedman M, Catania J. Interacting epidemics and gay men's health: a theory of syndemic production among urban gay men. In: Wolitski R, Stall R, Valdiserri R, editors. Unequal Opportunity: Health Disparities Affecting Gay and Bisexual Men in the United States. New York, NY: Oxford University Press; 2007.

45. Mustanski B, Garofalo R, Herrick A, Donenberg G. Psychosocial health problems increase risk for HIV among urban young men who have sex with men: Preliminary evidence of a syndemic in need of attention. Ann Behav Med 2007 Dec;34(1):37-45. [doi: 10.1007/BF02879919] [Medline: 17688395]

46. Parsons JT, Grov C, Golub SA. Sexual compulsivity, co-occurring psychosocial health problems, and HIV risk among gay and bisexual men: further evidence of a syndemic. Am J Public Health 2012 Jan;102(1):156-162. [doi:

10.2105/AJPH.2011.300284] [Medline: 22095358]

47. Meyer I. Minority stress and mental health in gay men. J Health Soc Behav 1995 Mar;36(1):38-56. [Medline: 7738327] 
48. Kelleher C. Minority stress and health: Implications for lesbian, gay, bisexual, transgender, and questioning (LGBTQ) young people. Couns Psychol Q 2009 Dec;22(4):373-379. [doi: 10.1080/09515070903334995]

49. D'Augelli AR, Hershberger SL, Pilkington NW. Suicidality patterns and sexual orientation-related factors among lesbian, gay, and bisexual youths. Suicide Life Threat Behav 2001;31(3):250-264. [doi: 10.1521/suli.31.3.250.24246] [Medline: 11577911]

50. Frost DM, Meyer IH. Internalized homophobia and relationship quality among lesbians, gay men, and bisexuals. J Couns Psychol 2009;56(1):97-109. [doi: 10.1037/a0012844]

51. Almeida J, Johnson RM, Corliss HL, Molnar BE, Azrael D. Emotional distress among LGBT youth: the influence of perceived discrimination based on sexual orientation. J Youth Adolesc 2009 Aug;38(7):1001-1014 [FREE Full text] [doi: 10.1007/s10964-009-9397-9] [Medline: 19636742]

52. Bidell M. School counselors and social justice advocacy for lesbian, gay, bisexual, transgender, and questioning students. J School Counsel 2011;9(10) [FREE Full text]

53. Compton SN, March JS, Brent D, Albano AM, Weersing R, Curry J. Cognitive-behavioral psychotherapy for anxiety and depressive disorders in children and adolescents: an evidence-based medicine review. J Am Acad Child Adolesc Psychiatry 2004 Aug;43(8):930-959. [doi: 10.1097/01.chi.0000127589.57468.bf] [Medline: 15266189 ]

54. Beck A. Cognitive Therapy And The Emotional Disorders. New York, NY: Plume; 1979.

55. Beck AT. Cognitive therapy: past, present, and future. J Consult Clin Psychol 1993;61(2):194-198. [doi: 10.1037/0022-006X.61.2.194] [Medline: $\underline{8473571]}$

56. Beck A, Alford B. Depression: Causes And Treatment, Second Edition. Pittsburgh, PA: University Of Pennsylvania Press; 2009.

57. Fenn K, Byrne M. The key principles of cognitive behavioural therapy. InnovAiT 2013 Sep 6;6(9):579-585. [doi: 10.1177/1755738012471029]

58. Martell C, Safren S, Prince S. Cognitive-Behavioral Therapies with Lesbian, Gay, and Bisexual Clients. New York, NY: Guilford Press; 2012.

59. Ross LE, Doctor F, Dimito A, Kuehl D, Armstrong MS. Can talking about oppression reduce depression? Modified CBT group treatment for LGBT people with depression. J Gay Lesbian Soc Serv 2008 Oct 11;19(1):1-15. [doi: $\underline{10.1300 / \mathrm{J} 041 \mathrm{v} 19 \mathrm{n} 01 \quad 01]}$

60. Hart TA, Tulloch TG, O'Cleirigh C. Integrated cognitive behavioral therapy for social anxiety and HIV prevention for gay and bisexual men. Cogn Behav Pract 2014 May;21(2):149-160. [doi: 10.1016/j.cbpra.2013.07.001]

61. Austin A, Craig SL. Empirically supported interventions for sexual and gender minority youth: a stakeholder driven model. J Evid Based Soc Work 2015 Apr 29;12(6):567-578. [doi: 10.1080/15433714.2014.884958]

62. Shoptaw S, Reback CJ, Peck JA, Yang X, Rotheram-Fuller E, Larkins S, et al. Behavioral treatment approaches for methamphetamine dependence and HIV-related sexual risk behaviors among urban gay and bisexual men. Drug Alcohol Depend 2005 May;78(2):125-134. [doi: 10.1016/j.drugalcdep.2004.10.004] [Medline: 15845315]

63. Craig SL, Austin A, Alessi E. Gay affirmative cognitive behavioral therapy for sexual minority youth: a clinical adaptation. Clin Soc Work J 2012 Dec 22;41(3):258-266. [doi: 10.1007/s10615-012-0427-9]

64. Champion JD, Collins JL. Comparison of a theory-based (AIDS Risk Reduction Model) cognitive behavioral intervention versus enhanced counseling for abused ethnic minority adolescent women on infection with sexually transmitted infection: Results of a randomized controlled trial. Int J Nurs Stud 2012 Feb;49(2):138-150. [doi: 10.1016/j.ijnurstu.2011.08.010] [Medline: 21937041]

65. Senyonyi RM, Underwood LA, Suarez E, Musisi S, Grande TL. Cognitive behavioral therapy group intervention for HIV transmission risk behavior in perinatally infected adolescents. Health 2012;04(12):1334-1345. [doi: 10.4236/health.2012.412195]

66. Hops H, Ozechowski TJ, Waldron HB, Davis B, Turner CW, Brody JL, et al. Adolescent health-risk sexual behaviors: effects of a drug abuse intervention. AIDS Behav 2011 Aug 11;15(8):1664-1676. [doi: 10.1007/s10461-011-0019-7] [Medline: 21833690]

67. Pachankis JE, Hatzenbuehler ML, Rendina HJ, Safren SA, Parsons JT. LGB-affirmative cognitive-behavioral therapy for young adult gay and bisexual men: a randomized controlled trial of a transdiagnostic minority stress approach. J Consult Clin Psychol 2015 Oct;83(5):875-889. [doi: 10.1037/ccp0000037] [Medline: 26147563]

68. McCart MR, Sheidow AJ, Letourneau EJ. Risk reduction therapy for adolescents: targeting substance use and HIV/STI-risk behaviors. Cogn Behav Pract 2014 May;21(2):161-175. [doi: 10.1016/j.cbpra.2013.10.001] [Medline: 25419101]

69. Lucassen MF, Merry SN, Hatcher S, Frampton CM. Rainbow SPARX: a novel approach to addressing depression in sexual minority youth. Cogn Behav Pract 2015 May;22(2):203-216. [doi: 10.1016/j.cbpra.2013.12.008]

70. Brown JL, Sales JM, Swartzendruber AL, Eriksen MD, DiClemente RJ, Rose ES. Added benefits: reduced depressive symptom levels among African-American female adolescents participating in an HIV prevention intervention. J Behav Med 2013 Dec 24;37(5):912-920. [doi: 10.1007/s10865-013-9551-4] [Medline: 24366521]

71. Safren SA, O'Cleirigh C, Tan JY, Raminani SR, Reilly LC, Otto MW, et al. A randomized controlled trial of cognitive behavioral therapy for adherence and depression (CBT-AD) in HIV-infected individuals. Health Psychol 2009 Jan;28(1):1-10 [FREE Full text] [doi: 10.1037/a0012715] 
72. Safren S, O'Cleirigh C, Bullis J, Otto M, Stein M, Pollack M. Cognitive behavioral therapy for adherence and depression (CBT-AD) in HIV-infected injection drug users: a randomized controlled trial. J Consult Clin Psychol 2012 Jun;80(3):404-415 [FREE Full text] [doi: 10.1037/a0028208] [Medline: 22545737]

73. Bullis JR, Fortune MR, Farchione TJ, Barlow DH. A preliminary investigation of the long-term outcome of the Unified Protocol for Transdiagnostic Treatment of Emotional Disorders. Comprehensive Psychiatry 2014;55(8):1920-1927.

74. Moradi B, Mohr JJ, Worthington RL, Fassinger RE. Counseling psychology research on sexual (orientation) minority issues: conceptual and methodological challenges and opportunities. J Couns Psychol 2009;56(1):5-22. [doi: 10.1037/a0014572]

75. Bonet L, Wells BE, Parsons JT. A positive look at a difficult time: a strength based examination of coming out for lesbian and bisexual women. J LGBT Health Res 2008 Oct 11;3(1):7-14. [doi: 10.1300/J463v03n01_02] [Medline: 18029311]

76. Morrison DM, Casey EA, Beadnell BA, Hoppe MJ, Gillmore MR, Wilsdon A, et al. Effects of friendship closeness in an adolescent group HIV prevention intervention. Prev Sci 2007 Dec;8(4):274-284. [doi: 10.1007/s11121-007-0075-4] [Medline: 17846890]

77. Compas BE, Connor-Smith JK, Saltzman H, Thomsen AH, Wadsworth ME. Coping with stress during childhood and adolescence: problems, progress, and potential in theory and research. Psychol Bull 2001;127(1):87-127. [doi: 10.1037/0033-2909.127.1.87] [Medline: 11271757]

78. Mustanski B, Newcomb ME, Garofalo R. Mental health of lesbian, gay, and bisexual youth: a developmental resiliency perspective. J Gay Lesbian Soc Serv 2011 Jan 1;23(2):204-225 [FREE Full text] [doi: 10.1080/10538720.2011.561474] [Medline: 21731405]

79. Craig SL. Affirmative supportive safe and empowering talk (ASSET): leveraging the strengths and resiliencies of sexual minority youth in school-based groups. J LGBT Issues Couns 2013 Oct;7(4):372-386. [doi: 10.1080/15538605.2013.839342]

80. Seiffge-Krenke I, Klessinger N. Long-term effects of avoidant coping on adolescents' depressive symptoms. J Youth Adolesc 2000 Dec;29(6):617-630. [doi: 10.1023/A:1026440304695]

81. Craig SL, McInroy L, Austin A, Smith M, Engle B. Promoting self-efficacy and self-esteem for multiethnic sexual minority youth: an evidence-informed intervention. J Soc Serv Res 2012 Oct;38(5):688-698. [doi: 10.1080/01488376.2012.718194]

82. Kulkin HS. Factors enhancing coping and mental health in lesbian youth: a review of the literature. J Homosex 2006 Jul 16;50(4):97-111. [doi: 10.1300/J082v50n04 05]

83. Matta R, Doiron C, Leveridge MJ. The dramatic increase in social media in urology. J Urol 2014 Aug;192(2):494-498. [doi: 10.1016/j.juro.2014.02.043] [Medline: 24576656]

84. Dentato MP, Craig SL, Smith MS. The vital role of social workers in community partnerships: the alliance for gay, lesbian, bisexual, transgender youth. Child Adolesc Soc Work J 2010 Jun 25;27(5):323-334. [doi: 10.1007/s10560-010-0210-0]

85. Cashman SB, Adeky S, Allen AJ, Corburn J, Israel BA, Montaño J, et al. The power and the promise: working with communities to analyze data, interpret findings, and get to outcomes. Am J Public Health 2008 Aug;98(8):1407-1417. [doi: 10.2105/AJPH.2007.113571] [Medline: 18556617]

86. Eaton AD, Tsang AK, Craig SL, Ginocchio GF. Peer researchers in post-professional healthcare: a glimpse at motivations and partial objectivity as opportunities for action researchers. Action Res J 2018 Nov 19:147675031881191. [doi: $10.1177 / 1476750318811913]$

87. Craig SL, Dentato MP, Iacovino GE. Patching holes and integrating community: a strengths-based continuum of care for lesbian, gay, bisexual, transgender and questioning youth. J Gay Lesbian Soc Serv 2015 Feb 20;27(1):100-115. [doi: $10.1080 / 10538720.2015 .988317]$

88. Graham R. The Health Of Lesbian, Gay, Bisexual, And Transgender People: Building A Foundation For Better Understanding. Washington, DC: National Academies Press; 2011.

89. Crisp C, McCave EL. Gay affirmative practice: a model for social work practice with gay, lesbian, and bisexual youth. Child Adolesc Soc Work J 2007 Sep 1;24(4):403-421. [doi: 10.1007/s10560-007-0091-z]

90. Handley MA, Schillinger D, Shiboski S. Quasi-experimental designs in practice-based research settings: design and implementation considerations. J Am Board Fam Med 2011;24(5):589-596 [FREE Full text] [doi: 10.3122/jabfm.2011.05.110067] [Medline: 21900443]

91. Tunis SR, Stryer DB, Clancy CM. Practical clinical trials: increasing the value of clinical research for decision making in clinical and health policy. J Am Med Assoc 2003 Sep 24;290(12):1624-1632. [doi: 10.1001/jama.290.12.1624] [Medline: 14506122]

92. Eaton AD, Chan Carusone S, Craig SL, Telegdi E, McCullagh JW, McClure D, et al. The ART of conversation: feasibility and acceptability of a pilot peer intervention to help transition complex HIV-positive people from hospital to community. BMJ Open 2019 Mar 30;9(3):e026674 [FREE Full text] [doi: 10.1136/bmjopen-2018-026674] [Medline: $\underline{\text { 30928956] }}$

93. Li F, Frangakis CE. Designs in partially controlled studies: messages from a review. Stat Methods Med Res 2016 Jul 2;14(4):417-431. [doi: 10.1191/0962280205sm405oa] [Medline: 16178140]

94. Brown CA, Lilford RJ. The stepped wedge trial design: a systematic review. BMC Med Res Methodol 2006 Nov 08;6(1):54. [doi: 10.1186/1471-2288-6-54] [Medline: 17092344] 
95. Bonell CP, Hargreaves J, Cousens S, Ross D, Hayes R, Petticrew M, et al. Alternatives to randomisation in the evaluation of public health interventions: design challenges and solutions. J Epidemiol Community Health 2009 Feb 12;65(7):582-587. [doi: 10.1136/jech.2008.082602] [Medline: 19213758]

96. Patsopoulos NA. A pragmatic view on pragmatic trials. Dialogues Clin Neurosci 2011;13(2):217-224 [FREE Full text] [Medline: 21842619]

97. Zuidgeest MG, Welsing PM, van Thiel GJ, Ciaglia A, Alfonso-Cristancho R, Eckert L, et al. Series: pragmatic trials and real world evidence: Paper 5. Usual care and real life comparators. J Clin Epidemiol 2017 Oct;90:92-98. [doi: 10.1016/j.jclinepi.2017.07.001] [Medline: 28694123]

98. Hussey MA, Hughes JP. Design and analysis of stepped wedge cluster randomized trials. Contemp Clin Trials 2007 Feb;28(2):182-191. [doi: 10.1016/j.cct.2006.05.007] [Medline: 16829207]

99. Eaton AD, Cattaneo JS, Watchorn JM, Bilbao-Joseph C, Bowler S, Hazelton M, et al. From serodiscordant to magnetic: the feasibility and acceptability of a pilot psychoeducational group intervention designed to improve relationship quality. Soc Work Groups 2017 Sep 22;41(4):323-335. [doi: 10.1080/01609513.2017.1369922] [Medline: 26281194]

100. Green LW. Making research relevant: if it is an evidence-based practice, where's the practice-based evidence? Fam Pract 2008 Sep 15;25(Supplement 1):i20-i24. [doi: 10.1093/fampra/cmn055] [Medline: 18794201]

101. Bavinton BR, Gray J, Prestage G. Assessing the effectiveness of HIV prevention peer education workshops for gay men in community settings. Aust N Z J Public Health 2013 Aug;37(4):305-310. [doi: 10.1111/1753-6405.12076] [Medline: 23895471]

102. Majer JM, Glantsman O, Palmer JS, Jason LA. Predictors of abstinence self-efficacy: examining the role of HIV-risk sexual behavior. J Soc Serv Res 2014 Aug 12;41(1):39-48. [doi: 10.1080/01488376.2014.935559] [Medline: 27226672]

103. Beck AT, Steer RA, Brown GK. Beck Depression Inventory: Second Edition Manual. London, UK: Pearson; 1996:490-498.

104. American Psychiatric Association. Diagnostic and Statistical Manual of Mental Disorders, 5th Edition: DSM-5. Washington, DC: American Psychiatric Association; 2013.

105. Rowley AA, Roesch SC, Jurica BJ, Vaughn AA. Developing and validating a stress appraisal measure for minority adolescents. J Adolesc 2005 Aug;28(4):547-557. [doi: 10.1016/j.adolescence.2004.10.010] [Medline: 16022889]

106. Carver CS. You want to measure coping but your protocol's too long: consider the brief COPE. Int J Behav Med 1997;4(1):92-100. [doi: 10.1207/s15327558ijbm0401 6] [Medline: 16250744$]$

107. Greenglass E, Schwarzer R, Jakubiec D. The proactive coping inventory (PCI): A multidimensional research instrument. 1999 Presented at: 20th International Conference of the Stress and Anxiety Research Society (STAR); July 12-14, 1999; Cracow, Poland.

108. Snyder CR, Harris C, Anderson JR, Holleran SA, Irving LM, Sigmon ST, et al. The will and the ways: development and validation of an individual-differences measure of hope. J Pers Soc Psychol 1991 Apr;60(4):570-585. [doi: 10.1037/0022-3514.60.4.570] [Medline: 2037968]

109. Nungesser L. Homosexual Acts, Actors and Identities. Westport, CT: Greenwood Press; 1983.

110. Tuckman BW. The scaling of mood. Educ Psychol Meas 2016 Sep 7;48(2):419-427. [doi: 10.1177/0013164488482014]

111. Williams DR, Yan Y, Jackson JS, Anderson NB. Racial differences in physical and mental health: socio-economic status, stress and discrimination. J Health Psychol 1997 Jul;2(3):335-351. [doi: 10.1177/135910539700200305] [Medline: 22013026]

112. Woodford MR, Chonody JM, Kulick A, Brennan DJ, Renn K. The LGBQ microaggressions on campus scale: a scale development and validation study. J Homosex 2015 Jul;62(12):1660-1687. [doi: 10.1080/00918369.2015.1078205] [Medline: 26226304]

113. Faul F, Erdfelder E, Lang A, Buchner A. G*Power 3: A flexible statistical power analysis program for the social, behavioral, and biomedical sciences. Behav Res Methods 2007 May;39(2):175-191. [doi: 10.3758/BF03193146]

114. King G, Honaker J, Joseph A, Scheve K. Analyzing incomplete political science data: an alternative algorithm for multiple imputation. Am Polit Sci Rev 2001;95(1):49-69 [FREE Full text]

115. Stansfield B, Hawkins K, Adams S, Bhatt H. A mixed linear modelling characterisation of gender and speed related changes in spatiotemporal and kinematic characteristics of gait across a wide speed range in healthy adults. Med Eng Phys 2018 Oct;60:94-102. [doi: 10.1016/j.medengphy.2018.07.015] [Medline: $\underline{\text { 30131278] }}$

116. Weirich S, Hecht M, Böhme K. Modeling item position effects using generalized linear mixed models. Appl Psychol Meas 2014 May 30;38(7):535-548. [doi: 10.1177/0146621614534955] [Medline: 30858809]

117. Boudiaf N, Laboissière R, Cousin ?, Fournet N, Krainik A, Baciu M. Behavioral evidence for a differential modulation of semantic processing and lexical production by aging: a full linear mixed-effects modeling approach. Neuropsychol Dev Cogn 2016 Nov 24;25(1):1-22. [doi: 10.1080/13825585.2016.1257100] [Medline: 27883290]

118. Bengtsson M. How to plan and perform a qualitative study using content analysis. NursingPlus Open 2016;2:8-14. [doi: 10.1016/j.npls.2016.01.001]
Abbreviations
CBT: cognitive behavioral therapy
CCAS: collaborating community agency site 
DSM: Diagnostic and Statistical Manual of Mental Disorders

LGBTQ: lesbian, gay, bisexual, transgender, and queer

LMM: linear mixed modeling

SGMY: sexual and gender minority youth

STI: sexually transmitted infections

SWWCD: stepped wedge wait-list crossover design

TAU/WL: treatment as usual or wait-list

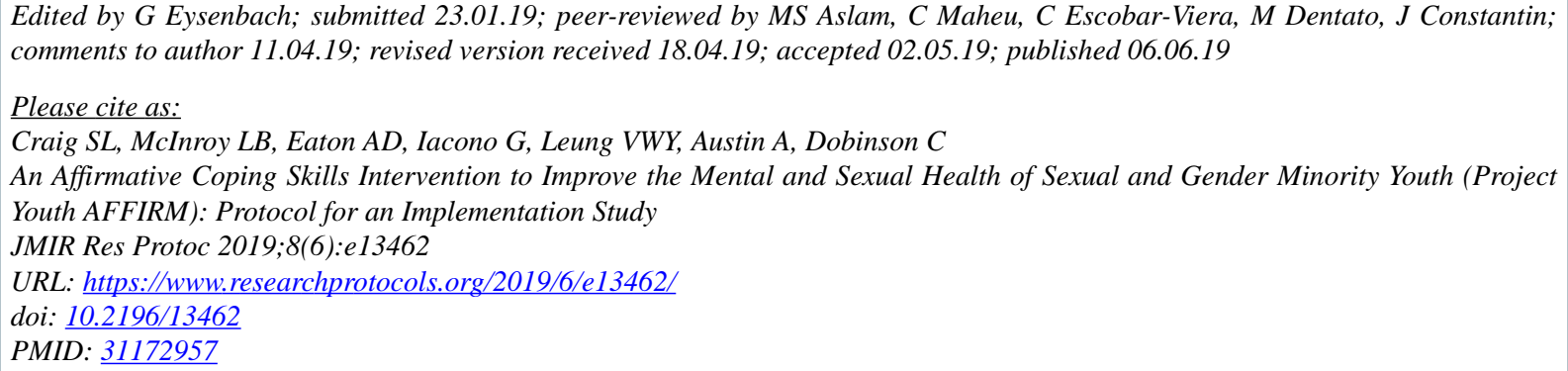

(C) Shelley L Craig, Lauren B McInroy, Andrew David Eaton, Gio Iacono, Vivian WY Leung, Ashley Austin, Cheryl Dobinson. Originally published in JMIR Research Protocols (http://www.researchprotocols.org), 06.06.2019. This is an open-access article distributed under the terms of the Creative Commons Attribution License (https://creativecommons.org/licenses/by/4.0/), which permits unrestricted use, distribution, and reproduction in any medium, provided the original work, first published in JMIR Research Protocols, is properly cited. The complete bibliographic information, a link to the original publication on http://www.researchprotocols.org, as well as this copyright and license information must be included. 